\title{
A newly identified Thr99fsX110 mutation in the PMP22 gene associated with an atypical phenotype of the hereditary neuropathy with liability to pressure palsies
}

\author{
Izabela Moszyńska, Dagmara Kabzińska, Elena Sinkiewicz-Darol and \\ Andrzej Kochański ${ }^{\bowtie}$ \\ Neuromuscular Unit, Mossakowski Medical Research Centre Polish Academy of Sciences, Warszawa, Poland
}

Received: 30 March, 2009; revised: 20 September, 2009; accepted: 12 October, 2009

available on-line: 15 October, 2009

\begin{abstract}
Hereditary neuropathy with liability to pressure palsies (HNPP) is manifested by a spectrum of phenotypes, from the classical HNPP course associated with intermittent nerve palsies to a neuropathy resembling Charcot-Marie-Tooth type 1 (CMT1) disease. The majority of HNPP cases are associated with submicroscopical deletions in the 17p11.2-p12 region containing the PMP22 gene, while PMP22 point mutations are rare, representing about $15 \%$ of HNPP cases. In this study, we present a patient manifesting with atypical HNPP phenotype associated with a new Thr99fsX110 mutation in the PMP22 gene. We conclude that all patients who fulfill the electrophysiological criteria of HNPP, even if they lack the typical HNPP phenotype, should be tested for point mutations in the PMP22 gene.
\end{abstract}

Keywords: HNPP neuropathy, PMP22 gene mutations

\section{INTRODUCTION}

Hereditary neuropathy with liability to pressure palsies (HNPP) is a heterogeneous clinical entity that manifests with a wide phenotypic spectrum.

In a large study encompassing 99 individuals affected with HNPP, seven different phenotypes of HNPP have been described.

The majority of patients affected with HNPP present with recurrent peripheral nerve palsies.

A smaller group manifest with a chronic sensory neuropathy. Finally, 20\% of patients have been shown to be asymptomatic carriers of the PMP22 gene deletion (Mouton et al., 1999).

A vast majority of HNPP cases are caused by submicroscopic deletion in the 17p11.2-p12 region encompassing the PMP22 gene (Chance et al., 1993). In 1993, Nicholson and coworkers reported a first point mutation in the PMP22 gene that caused
HNPP (Nicholson et al., 1994). To date, only 13 mutations in the PMP22 gene have been reported causing the HNPP phenotype despite 16 years of systematic studies (IPNMDB database: molgen-www.uia. ac.be/CMT Mutations).

In this report, we characterized a patient manifesting with an atypical form of HNPP neuropathy caused by a new Thr99fsX110 mutation in the PMP22 gene.

Family report

The family came from the south-east part of Poland. The affected family members included the proband, his father and grandfather (Fig. 1a). The proband (IV:10) was born following a normal, uneventful pregnancy. His motor development was normal but according to his father he stumbled and fell frequently. Currently, at the age of 17 years, the

\footnotetext{
${ }^{\square}$ Corresponding author: Andrzej Kochański, Neuromuscular Unit, Mossakowski Medical Research Centre Polish Academy of Sciences, A. Pawińskiego 5, 02-106 Warszawa; tel./fax: (48) 22658 4501; e-mail: andko@cmdik.pan.pl

Abbreviations: CMAP, compound muscle action potential; CMT, Charcot-Marie-Tooth disease; DML, distal motor lateney; EMG, electromyography; GJB1, gap junction protein, beta 1; HDA, heteroduplex analysis; HNPP, hereditary neuropathy with liability to pressure palsies; IPNMDB, Inherited Peripheral Neuropathies Mutation Database; MNCV, motor nerve conduction velocity; RFLP, restriction fragment length polymorphism PMP22, peripheral myelin protein 22; SNCV, sensory nerve conduction velocity.
} 
proband complains of pain in the legs. Clinical examination at 17 years has revealed no abnormalities except a symmetrical pes cavus deformity.

No episodes of peripheral nerve palsies have been observed in the proband until now.

The proband's father (III:9) aged 44 years was completely asymptomatic until the age of 25 years. At that time, he experienced an asymmetrical right foot drop which has not resolved until now.

In neurological examination at the age of 44 years, he manifested symmetrical pes cavus deformity that was more pronounced on the right side. He shows gait difficulties with a right foot drop. Ankle reflexes are absent. The patient shows symmetrical muscle wasting in the distal parts of the lower limbs. A mild wasting of the small hand muscles is also visible.

\section{Electrophysiological findings}

Neurophysiological studies were carried out on the proband (IV:10) in 2007 and his father (III:9) in 1991. Mixed axonal-demyelinating neuropathy was diagnosed in the proband in the neurographic examination and in the archival EMG examination performed on the father.

In the upper limbs of the proband, compound muscle action potential (CMAP) amplitudes were in the normal range (median $11.4 \mathrm{mV}$, ulnar $7.4 \mathrm{mV}$ ). Motor nerve conduction velocities (MNCV) were slightly reduced (median $44 \mathrm{~m} / \mathrm{s}$, ulnar $46 \mathrm{~m} / \mathrm{s}$ ). The latencies in the median and ulnar nerves were prolonged at $6.4 \mathrm{~ms}$ and $3.8 \mathrm{~ms}$, respectively.

The sensory nerve conduction velocities in the upper limbs were reduced to $34 \mathrm{~m} / \mathrm{s}$ in the median and in ulnar nerves.

In the lower limbs, the sural amplitude was slightly reduced $(6 \mu \mathrm{V})$ both in the right and left sural nerve. Sensory nerve conduction $(\mathrm{SNCV})$ in the sural nerve was symmetrically reduced $(34 \mathrm{~m} / \mathrm{s})$.

The superficial peroneal nerve amplitudes were not recordable. MNCV values in the peroneal and tibial nerves were symmetrically reduced to 27 $\mathrm{m} / \mathrm{s}$ and $32 \mathrm{~m} / \mathrm{s}$, respectively. The MNCV values were markedly reduced at the head of fibula $(16 \mathrm{~m} / \mathrm{s}$ and $28 \mathrm{~m} / \mathrm{s}$ in the right and left peroneal nerves, respectively). EMG showed chronic denervation that was more pronounced in the distal lower limb muscles.

\section{SUBJECTS, MATERIALS AND METHODS}

Patients. Approval (No. 120/2008) was obtained from the joint medical and ethics committee at the Warsaw Medical University to perform this clinical and genetic study.
DNA was extracted from blood samples obtained with informed consent from the individuals concerned.

Eighty families were selected from 400 Charcot-Marie-Tooth (CMT) pedigrees for this study on the basis of the absence of the PMP22 gene duplication/deletion.

High molecular mass DNA was extracted from lymphocytes of 89 CMT affected individuals representing $80 \mathrm{CMT}$ families.

Methods. RFLP analysis was performed using primers, PCR reaction and digestion conditions reported by Stronach and colleagues with some modifications, i.e. PCR amplification for CMT1A and HNPP testing was carried out in 12.5 $\mu \mathrm{L}$ volumes. From 6 to $10 \mu \mathrm{L}$ of amplified products was digested with EcoRI according to the manufacturer's instruction (Stronach et al., 1999).

Q-PCR analysis was carried out in conditions previously described by Aarskog and Vedeler (2000) with some modifications. The TaqMan probe for the PMP22 gene contains 5'FAM fluorophore as a reporter and 3'TAMRA as a quencher and the TaqMan probe for the human serum albumin gene contains $5^{\prime}$ VIC as a reporter and 3'TAMRA as a quencher.

The sensitivity of the single strand conformation polymorphism method (SSCP) was tested prior to the screening of DNA samples. Briefly, PCR amplification was performed for DNA samples carrying five mutations previously detected in our laboratory in the GJB1 gene. In the validation approach, four of these mutations were confirmed.

Five exons of the coding sequence of the PMP22 gene were amplified by PCR. A standard PCR reaction was carried out in a $25 \mu \mathrm{l}$ volume containing: $100 \mathrm{ng}$ of genomic DNA template, 5 mmol dNTPs and 4 pmol of each primer.

PCR was performed for 33 cycles of $1 \mathrm{~min}$ at $95^{\circ} \mathrm{C}, 1 \mathrm{~min}$ at the respective annealing temperature (exons $1,61^{\circ} \mathrm{C} ; 2,55^{\circ} \mathrm{C} ; 3,58^{\circ} \mathrm{C}$ ), and $90 \mathrm{~s}$ at $72^{\circ} \mathrm{C}$.

Both SSCP and heteroduplex analysis (HDA) were performed to screen PCR-products. The PCR products were mixed with SSCP and HDA buffers.

After denaturation for $5 \mathrm{~min}$ at $95^{\circ} \mathrm{C}$, samples were rapidly cooled on ice.

For HDA analysis, the samples $(3 \mu \mathrm{l})$ were mixed with loading buffer ( $30 \%$ glycerol, $0,25 \%$ bromophenol blue, $0,25 \%$ xylene cyanol) and denatured for $6 \mathrm{~min}$ at $95^{\circ} \mathrm{C}$. For renaturation, samples were placed at $65^{\circ} \mathrm{C}$ for $45 \mathrm{~min}$. The samples were loaded on non-denaturing $6 \%$ polyacrylamide gels and electrophoresed in the INGENY 


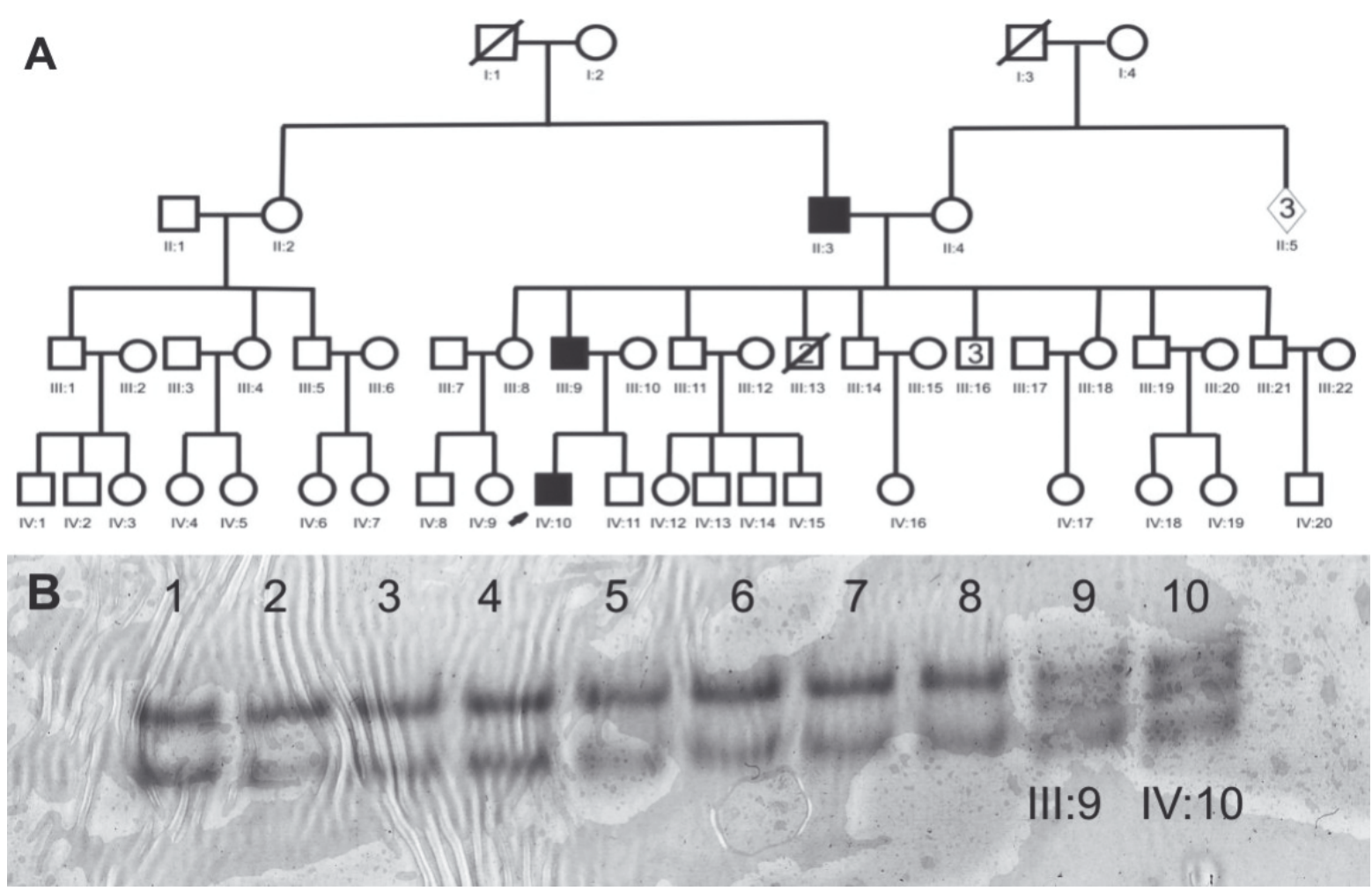

Figure 1. Family tree and results of SSCP screening.

A. Pedigree of the CMT family associated with the new Thr99fsX110 mutation in the PMP22 gene. The proband is indicated with an arrow. Females are denoted by circles and males by squares. A filled symbol denotes a CMT-affected patient. Deceased individuals are marked with a diagonal line. B. Results of SSCP analysis performed for the proband (IV:9), his father (III:10) and healthy controls. Altered SSCP migration was identified due to a heterozygous single nucleotide deletion of $\mathrm{T}$ (lanes 9 and 10).

system for $20 \mathrm{~h}$ at $150 \mathrm{~W}$. The gels were silverstained and dried.

Direct sequencing analysis of the PCR products with an altered migration pattern was performed on an 3730/xl DNA analyzer using the BigDye Terminator v3.1 Cycle Sequencing Kit (Applied Biosystems).

\section{RESULTS AND DISCUSSION}

Direct sequencing of the PMP22 gene revealed a heterozygous single nucleotide deletion of $\mathrm{T}$ in position 297 (297T $\Delta)$, resulting in a frameshift and consequent appearance of a STOP codon at the nucleotide 110 (Thr99fsX110) in the proband (IV:10) and his father (III:9).

Hereditary neuropathy with liability to pressure palsies (HNPP) was described 62 years ago but is still underdiagnosed.

The most likely reason of this relatively low number of HNPP diagnoses may be related to a spectrum of phenotypes that do not fit the classical HNPP course.

The new PMP22 gene mutation in the patient reported by us was not detected on the ba-
A

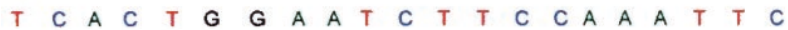
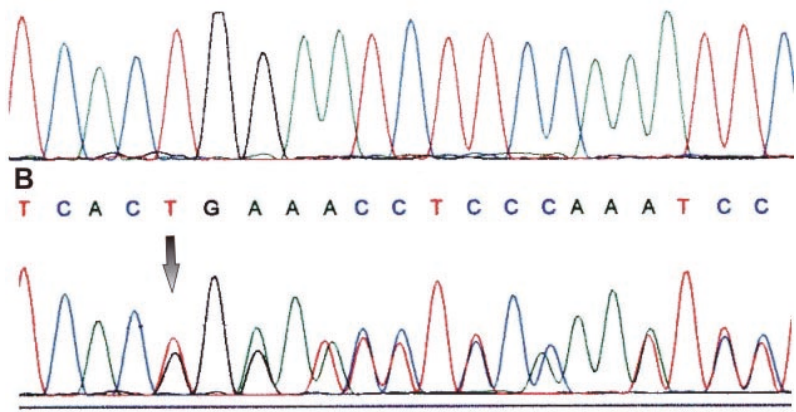

c

TCACTGAAACCTCC CAATTCC $\checkmark$

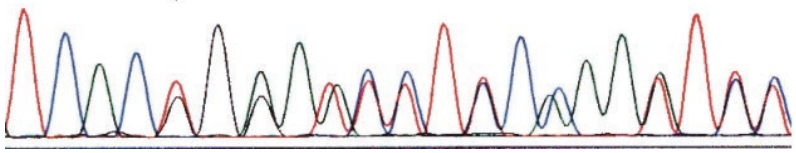

Figure 2. Identification of the 297T $\Delta$ (Thr99fsX110) PMP22 gene mutation.

Direct sequencing revealed a heterozygous one single nucleotide deletion of $\mathrm{T}$ at the nucleotide 297 of the PMP22 gene. A. Wild type sequence; B. Heterozygous 297T $\Delta$ in the proband (IV:10) marked by arrow; C. Heterozygous 297T $\Delta$ in the father of proband (III:9) marked by arrow. 
sis of previous HNPP clinical diagnosis, but was a result of random screening of the PMP22 gene sequence in 89 CMT-affected patients negative for the PMP22 gene duplication/deletion.

In fact, the patient reported in our study did not present with clinical features of HNPP, i.e. recurrent painless palsies of the peripheral nerves, but only with a symmetrical pes cavus deformity.

In a large comparative study of 70 HNPPaffected patients carrying the PMP22 gene deletion, only $20 \%$ displayed a pes cavus deformity (Lenssen et al., 1998).

In contrast to the clinical evaluation, EMG examination revealed three typical features of HNPP delineated by Mouton et al. (1999).

The proband showed: (i) increased distal motor latencies in both median nerves, (ii) slowed SNCV in both median nerves across the carpal tunnel in the palm-wrist segment, and (iii) prolonged DML and slowed MNCV in the right peroneal nerve.

Due to a lack of recurrent nerve palsies in the proband, we would rather not classify this entity as HNPP. We propose to describe this phenotype as a mild demyelinating neuropathy associated with the Thr99fsX110 mutation in the PMP22 gene.

We could not exclude the possibility that some PMP22 gene variants were not detected in our study. The sensitivity of the SSCP/HDA screening, as validated in our material, is $80 \%$, which means that $20 \%$ of PMP22 gene mutations may have been missed.

However, only 13 mutations in the PMP22 gene have been detected until now in patients affected with HNPP, and thus it seems unlikely that another mutation could be present in our set of 89 DNA samples.

The pathogenic effect of the Thr99fsX110 mutation seems to be obvious. Nevertheless this mutation was transmitted through three generations in the family reported in our study.

Due to the mild phenotype of CMT caused by the Thr99fsX110 mutation, we suggest a loss of function effect of this variant rather than a dominant negative effect.

Interestingly, the previously reported PMP22 mutations associated with the CMT phenotype have been postulated to act via a dominant negative mechanism. All 13 heterozygous point mutations in the PMP22 gene were detected in severely affected patients manifesting with a Dejerine-Sottas phenotype, supporting the hypothesis of the dominant negative effect (IPNMDB database).

Our study further documents the variability of CMT/HNPP phenotypes associated with point mutations of the PMP22 gene.

\section{Acknowledgements}

This study was supported by grant of the Ministry of Science and Higher Education No. NN 402276336 .

The authors are grateful to Mrs. Jadwiga Kędzierska for skillful technical assistance.

\section{REFERENCES}

Aarskog NK, Vedeler CA (2000) Real-time quantitative polymerase chain reaction. A new method that detects both the peripheral myelin protein 22 duplication in Charcot-Marie-Tooth type 1A disease and the peripheral myelin protein 22 deletion in hereditary neuropathy with liability to pressure palsies. Hum Genet 170: 494-498.

Chance PF, Alderson MK, Leppig KA, Lensch MW, Matsunami N, Smith B, Swanson PD, Odelberg SJ, Disteche CM, Bird TD (1993) DNA deletion associated with hereditary neuropathy with liability to pressure palsies. Cell 72: 143-151.

Lenssen PPA, Gabreels-Festen AAWM, Valentijn LJ, Jongen PJ, van Beersum SE, van Engelen BG, van Wensen PJ, Bolhuis PA, Gabreëls FJ, Mariman EC (1998) Hereditary neuropathy with liability to pressure palsies. Phenotypic differences between patients with the common deletion and a PMP22 frame shift mutation. Brain 121: 1451-1458.

Mouton P, Tardieu S, Gouider R, Birouk N, Maisonobe T, Dubourg O, Brice A, LeGuern E, Bouche P (1999) Spectrum of clinical and electrophysiologic features in HNPP patients with the 17p11.2 deletion. Neurology 52: 1440-1446.

Nicholson GA, Valentijn LJ, Cherryson AK, Kennerson ML, Bragg TL, DeKroon RM, Ross DA, Pollard JD, McLeod JG, Bolhuis PA, Baas F (1994) A frame shift mutation in the PMP22 gene in hereditary neuropathy with liability to pressure palsies. Nat Genet 6: 263-266.

Stronach EA, Clark C, Bell Ch, Löfgren A, McKay NG, Timmerman V, Van Broeckhoven C, Haites N (1999) Novel PCR-based diagnostic tools for Charcot-MarieTooth type 1A and hereditary neuropathy with liability to pressure palsies. J Peripher Nerv Syst 4: 117-122. 